\title{
Correlates of alcohol consumption among Germans in the second half of life. Results of a population-based observational study
}

\author{
André Hajek $^{1^{*}} \mathbb{D}$, Jens-Oliver Bock', Siegfried Weyerer ${ }^{2}$ and Hans-Helmut König ${ }^{1}$
}

\begin{abstract}
Background: Several studies have investigated the predictors of alcohol consumption behavior among adolescents and young adults. However, the body of evidence about the relationship between in particular psychological factors and alcohol consumption among individuals in the second half of life is still limited. Hence, we aimed at identifying factors associated with alcohol consumption among individuals aged 40 and above, especially focusing on psychological correlates.

Methods: Data were derived from a population-based sample of community-dwelling individuals aged 40 to 95 years ( $n=7820$ ) in Germany. Alcohol consumption was rated as 'never' (never drinkers), 'rarer than once a month', 'one to three times a month', 'once a week', 'several times a week' (occasional drinkers), and 'daily' (daily drinkers). Socio-economic factors, the illness level and physical activity were considered as possible determinants of alcohol consumption. In addition, positive and negative affect, life satisfaction, optimism, self-esteem, self-efficacy, and self-regulation were included as psychological factors. Multinomial regressions were used to identify factors associated with drinking behavior.

Results: $12.0 \%$ of the individuals were daily drinkers, $76.5 \%$ were occasional drinkers, and $11.5 \%$ of the individuals never drank alcohol. After adjusting for various potential confounders, multinomial logistic regressions revealed that, compared with never drinking, occasional and daily drinking were positively associated with a decreased loneliness, a higher life satisfaction, a higher positive affect, a higher optimism, a higher self-efficacy (occasional drinkers), a higher self-esteem, and less perceived stress. In addition, occasional and daily drinking were positively associated with less physical illnesses, male gender, and income as compared with never drinking.

Conclusions: The current study extends the existing literature on alcohol consumption behavior by new insights of correlates of drinking behavior among individuals in the second half of life. Since interventions are available to address this risk factor, this might help to identify individuals with increased alcohol consumption.
\end{abstract}

Keywords: Alcohol, Psychological factors, German Ageing Survey

\section{Background}

Alcohol consumption is associated with a tremendous burden of chronic disease and disability [1]. For example, worldwide 3.3 million deaths every year are caused by harmful use of alcohol, which equally leads to various non-communicable diseases, injuries, and infectious diseases such as tuberculosis [2].

\footnotetext{
* Correspondence: a.hajek@uke.de

1 Department of Health Economics and Health Services Research, Hamburg Center for Health Economics, University Medical Center Hamburg-Eppendorf, Hamburg, Germany

Full list of author information is available at the end of the article
}

Risk factors of alcohol consumption and risky alcohol use have been extensively studied. For example, it has been shown that undesirable life events, e.g., divorce, are associated with increased alcohol consumption [3]. Furthermore, a substantial body of evidence has found that psychological factors are associated with alcohol consumption among adolescents and young adults [4-9]. For example, it has been shown that self-regulation was negatively associated with alcohol consumption in adolescents and students $[7,10]$. It has also been reported that satisfaction with life is negatively associated with regular alcohol use in adolescents [9]. 
However, the body of evidence about the relationship between in particular psychological factors and alcohol consumption among individuals in the second half of life is still limited [11-13]. This is despite the fact that several stressful life events occur in the second half of life such as bereavement, social isolation or disability in one's self or family members, which might be associated with alcohol intake. In addition, because of the demographic ageing in Germany, the number of older people is projected to rise substantially, underlining the meaning of alcohol consumption in old age. Therefore, it is important to study individuals in the second half of life (40 years and over) [14]. Furthermore, in older age, increased or daily alcohol consumption has been found to be associated with numerous adverse health outcomes including insomnia, frequent falls or depression [15]. This is in accordance with, for example, the guidelines of New Zealand [16], suggesting at least two alcohol-free days per week.

Thus, the aim of the current study was to identify factors related to alcohol consumption, particularly focusing on psychological factors, using a population-based sample of individuals aged 40 and over. This lack of knowledge is important to address because it might help to characterize individuals with risky alcohol consumption.

It has been shown that life satisfaction is negatively associated with regular alcohol use in a younger sample [9]. Thus, we hypothesize that life satisfaction as well as positive affect and optimism are negatively associated with alcohol consumption. In contrast, we hypothesize that negative affect and loneliness are positively associated with alcohol consumption. This appears plausible because depressive symptoms (which are strongly associated with negative affect, loneliness and stress) are associated with increased alcohol consumption [17]. A previous study has shown that self-regulation was negatively associated with alcohol consumption [7]. In line with this study, we hypothesize that self-regulation is negatively associated with alcohol consumption. This appears plausible because individuals scoring high in self-regulation delay shortterm goals (e.g., drink in a pub) to achieve long-term goals (e.g., stay healthy). Moreover, in accordance with previous findings [18], we hypothesize that self-esteem is negatively associated with alcohol consumption. In addition, it has been demonstrated that increased alcohol consumption is associated with low self-efficacy [19]. In line with these findings, we hypothesize that self-efficacy is negatively associated with alcohol consumption.

\section{Methods}

\section{Study population}

Participants were from the fifth wave (2014) of the nationwide German Aging Survey (DEAS), a large populationbased observational study with community-dwelling participants at the age of 40 years and above. The recruitment for the baseline wave took place in 1996; data for further waves were collected in 2002 (second wave), 2008 (third wave), 2011 (fourth wave), and in 2014. The interval between the waves was reduced from 6 to 3 years in order to reduce attrition and to capture midterm changes adequately [20].

National probability sampling was used to determine potential participants via registry offices in order to obtain representative samples for the older German population. The individuals were offered participation via mail.

Each of the follow-up waves comprised longitudinal panel samples with participants who had already taken part before in the study and cross-sectional samples with participants taking part for the first time (except for wave 4 , which is a pure panel survey). The DEAS has a cohort-sequential design, linking cross-sectional samples with longitudinal samples.

Nearly 5200 individuals were interviewed in wave 2, 8200 individuals took part in wave 3 , approximately 4850 individuals were interviewed in wave 4 and 10,324 individuals took part in wave 5. More than 1526 individuals from baseline were re-interviewed in wave 2 . While nearly 2000 individuals were re-interviewed in wave 3 , about 6200 individuals took part for the first time. While about 6000 individuals took part for the time in wave 5, more than 4000 individuals were re-interviewed. Further details (e.g., sampling composition) were provided in detail elsewhere [20].

In 2014, the response rates for the panel sample was $61 \%$, for the cross-sectional sample $25 \%$, respectively. Baseline participants who provided written informed consent were contacted again in order to participate in the other waves. Compared with other European surveys, DEAS response rates are rather low [21]. However, the response rates of the DEAS are similar to comparable German surveys [22]. A decrease in participation rates in surveys in Western countries can be observed in the last years. However, this phenomenon is most pronounced in Germany [21]. The DEAS made efforts to alleviate this trend. For example, the incentives for respondents were increased (since 2008: €10). Notwithstanding, response rates for baseline samples decreased from about 50\% (1996) to the figure reported above.

For this year, a total of $n=7820$ individuals took part in the study and provided information on alcohol consumption (gross sample: $n=23,984$ ). Alcohol consumption was not assessed in former waves. The survey consisted of a face-to-face computer-assisted personal interview at the participants' homes and a drop-off questionnaire $(n=7952)$. Written informed consent was obtained from all participants.

\section{Dependent variable}

Alcohol intake (exact wording: How often do have a drink containing alcohol (e.g. beer, wine, sparkling wine, 
spirits, long drinks) was self-reported as 'never' (nondrinkers); 'rarer than once a month', 'one to three times a month,' 'once a week', or 'several times a week' (collapsed into the category occasional drinkers); and 'daily' (daily drinkers). The threshold for a "risky" alcohol intake was considered as daily alcohol consumption ("non-risky": otherwise) [15]. A time frame (e.g., last 6 months or last year) was not specified. Thus, ex-drinkers would fall into the category of non-drinkers. This will be addressed in the discussion section.

\section{Independent variables: Psychological factors}

Loneliness was measured using a short version of the widely used 11-item De Jong Gierveld Loneliness Scale [23]. It has been proven to be valid [23, 24]. Cronbach's alpha was .83 in our sample. Further details concerning all psychological measures used in the current study are depicted in Table 1. The well-established Satisfaction with Life Scale (SWLS) [25] was used to assess the satisfaction with life, with Cronbach's alpha $=.86$. Positive and negative affect were assessed using the Positive and Negative Affect Schedule (PANAS) [26], which has very good psychometric properties [27]. Cronbach's Alpha was .87 . Optimism was quantified using a validated scale by Brandtstädter and Wentura [28]. Cronbach's alpha was .84. Using the widely-used scale by Schwarzer and Jerusalem [29], self-efficacy was assessed. Cronbach's alpha was .75. The well-established Rosenberg scale [30] was used to measure self-esteem. Cronbach's alpha was .84. Stress was measured using a scale by Cohen et al. [31], with Cronbach's alpha $=.70$. According to a scale by Ziegelmann and Lippke [32] which was based on a scale developed by Freund and Baltes [33], self-regulation was operationalized. Cronbach's alpha was .78.

The instruments used to quantify the psychological factors in the present study are widely used and accepted. They have also been validated in German language. For example, the scale to quantify optimism has been validated by Brandtstädter and Wentura [28]. Moreover, it has for example been shown that the self-efficacy scale is valid [34].

\section{Independent variables: Other variables}

Moreover, independent variables were included as follows: age, gender, and marital status (married and living together with spouse; others (married and living separately, divorced, widowed, and single), region (West and East Germany) and individual monthly net equivalence income (OECD scale). In addition, physical activity ('never,' 'rarer than once a month,' 'one to three times a month', 'once a week, 'several times a week', and 'daily') was included. Furthermore, the sum of chronic conditions such as cancer or bad circulation (no; yes) were included, ranging from 0 to 11 .
It is widely acknowledged that alcohol intake is strongly associated with depression. However, the causal pathway is not entirely clear and there is evidence that increased alcohol consumption can cause depression [35, 36]. For this reason, depression was solely added to the main model in additional analysis. Depression (sum score $\geq 18$ ) was quantified using the Center for Epidemiological Studies Depression Scale (15 items, 0-45).

Furthermore, in additional analysis, our main regression model was stratified by age ( $<65$ years; $\geq 65$ years) because these two age groups might differ in many ways (e.g. social ties, less structured days in retirement or less work-related activities) [37].

\section{Statistical analysis}

Analyses of variance were used for the continuous variables, and chi-squared tests for all other variables. Multinomial logistic regressions were performed, with (1) non-drinkers (reference category), (2) occasional drinkers, and (3) daily-drinkers. Furthermore, occasional drinking was used as reference category (results not shown, but available upon request). The criterion for statistical significance was set at $p<.05$. All analyses were performed using Stata 14.0 (StataCorp, College Station, Texas, USA). The psychological factors were entered separately in the regression models because they are strongly correlated with each other.

\section{Results \\ Sample characteristics}

Table 2 shows the sample characteristics, stratified by drinking status. A total of $n=7820$ participants provided data on alcohol consumption. $12.0 \%$ of these individuals were daily drinkers, $76.5 \%$ were occasional drinkers, and $11.5 \%$ never drank alcohol. These groups differ significantly from each other regarding all socio-economic variables, the illness level, status of activity, and all psychological factors except self-regulation.

The mean age of all participants was 65.5 years; it was higher in the non-drinking and daily drinking group than in the occasional drinking group (post hoc contrasts were performed, but not shown here). About $75 \%$ of daily drinkers were male, although the proportion of men was only $53 \%$ in the whole sample. Among those who never drank, the proportion of men was only $39 \%$. The status of being married and living together with the spouse increased from non-drinking, to occasional drinking and to daily drinking status. The same applied to income that increased from $€ 1548$ (non-drinking) to $€ 2206$ (daily drinking) per month. Both non-drinkers and daily drinkers suffered from more chronic physical conditions than occasional drinkers did.

With respect to the psychological factors, loneliness was more pronounced in the daily and non-drinking 
Table 1 Psychological factors. Items and explanations

\begin{tabular}{|c|c|}
\hline Psychological factors & Items and explanations \\
\hline $\begin{array}{l}\text { Loneliness (De Jong } \\
\text { Gierveld \& Van Tilburg, } \\
\text { 2006) [23] }\end{array}$ & $\begin{array}{l}\text { Emotional loneliness } \\
\text { 1. I experience a general sense of emptiness. } \\
\text { 2. I miss having people around. } \\
\text { 3. I often feel rejected. } \\
\text { Social loneliness } \\
\text { 1. There are plenty of people I can rely on when } \\
\text { I have problems. }\left(^{*}\right) \\
\text { 2. There are many people I can trust completely. } \\
\left(^{*}\right) \\
\text { 3. There are enough people I feel close to. }\left(^{*}\right) \\
\text { Scale represents the mean of at least } 3 \text { required } \\
\text { valid items, } \\
3 \text { items have been recoded. } \\
1=\text { strongly agree } \\
2=\text { agree } \\
3=\text { disagree } \\
4=\text { strongly disagree } \\
\text { High values represent high loneliness. }\end{array}$ \\
\hline $\begin{array}{l}\text { Life satisfaction (SWLS, } \\
\text { Pavot \& Diener, 1993) [25] }\end{array}$ & $\begin{array}{l}\text { 1. In most ways my life is close to my ideal. } \\
\text { 2. The conditions of my life are excellent. } \\
\text { 3. I am satisfied with my life. } \\
\text { 4. So far I have gotten the important things I } \\
\text { want in life. } \\
\text { 5. If I could live my life over, I would change } \\
\text { almost nothing. } \\
\text { Scale represents the mean of at least } 3 \text { required } \\
\text { valid items, all items } \\
\text { have been recoded. } \\
1=\text { strongly agree } \\
2 \text { = agree } \\
3=\text { neither agree nor disagree } \\
4=\text { disagree } \\
5 \text { = strongly disagree } \\
\text { High values represent high life satisfaction. }\end{array}$ \\
\hline
\end{tabular}

Negative affect (PANAS, Watson et al., 1988) [26]

Positive affect (PANAS, Watson et al., 1988) [26]
In the following you will find a number of words that describe different feelings and emotions Please indicate to what extent you have felt this way during the past few months.

1. Distressed

2. Upset

3. Guilty

4. Scared

5. Hostile

6. Irritable

7. Ashamed

8. Nervous

9. Jittery

10. Afraid

Scale represents the mean of at least 3 required valid items.

$1=$ very slightly or not at all

$2=\mathrm{a}$ little

$3=$ moderately

4 = quite a bit

$5=$ extremely

High values on the NA scale represent high

frequency of negative emotions.

In the following you will find a number of words that describe different feelings and emotions.

Please indicate to what extent you have felt this way during the past few months.

1. Enthusiastic

2. Excited

3. Strong

4. Interested

5. Proud

6. Alert

7. Inspired

8. Determined

9. Attentive

10. Active

Table 1 Psychological factors. Items and explanations (Continued)

Scale represents the mean of at least 3 required valid items.

$1=$ very slightly or not at all

$2=\mathrm{a}$ little

$3=$ moderately

$4=$ quite $\mathrm{a}$ bit

$5=$ extremely

High values on the PA scale represent high frequency of positive emotions.

Optimism (Brandtstädter \& 1. I am looking forward to the life ahead of Wentura, 1994) [28] me. $\left(^{*}\right)$

2. For me the future is full of hope. $\left(^{*}\right)$

3. Thinking about my future makes me worry.

4. I look to the future with confidence. $(*)$

5. The future holds a lot of good in store for me. $(*)$

Scale represents the mean of at least 3 required valid items, 4 items

have been recoded.

$1=$ strongly agree

$2=$ agree

$3=$ disagree

$4=$ strongly disagree

High values represent high optimism.

Self-efficacy (Schwarzer \& 1. It is easy for me to stick to my aims and Jerusalem, 1999) [29] accomplish my goals.

2. I can usually handle whatever comes my way.

3. I can solve most problems if I invest the necessary effort.

4. If I am in trouble, I can usually think of a solution.

5. When I am confronted with a problem, I can usually find several solutions

Scale represents the mean of at least 3 required valid items, all items

have been recoded.

$1=$ strongly agree

$2=$ agree

$3=$ disagree

4 = strongly disagree

High values represent high self-efficacy.

Self-esteem

(Rosenberg, 1965) [30]

Stress (Cohen et al., 1983) [31]
1. On the whole, I am satisfied with myself. $\left(^{*}\right)$

2. I am able to do things as well as most other people. $\left(^{*}\right)$

3. All in all, I am inclined to feel that I am a failure.

4. I feel that I have a number of good qualities. $(*)$

5. I certainly feel useless at times.

6. I feel that I'm a person of worth, at least on an equal plane with others. $\left(^{*}\right)$

7. I feel I do not have much to be proud of. 8. I take a positive attitude toward myself. $(*)$

9. I wish I could have more respect for myself.

10. At times I think I am no good at all.

Scale represents the mean of at least 3 required valid items, 5 items have been recoded.

$1=$ strongly agree

$2=$ agree

$3=$ disagree

4 = strongly disagree

High values represent high self-esteem.

1. In the last month, how often have you felt that you were unable to control the important things in your life?

2. In the last month, how often have you felt confident about your ability to handle your personal problems? $\left.{ }^{*}\right)$

3. In the last month, how often have you felt that things were going your way? $\left(^{*}\right)$ 
Table 1 Psychological factors. Items and explanations (Continued)

\begin{tabular}{|c|c|}
\hline & $\begin{array}{l}\text { 4. In the last month, how often have you felt } \\
\text { difficulties were piling up so high that you } \\
\text { could not overcome them? } \\
\text { Scale represents the mean of at least } 2 \text { required } \\
\text { valid items, } 2 \text { items have been recoded. } \\
1 \text { = never } \\
2 \text { = seldom } \\
3=\text { sometimes } \\
4=\text { often } \\
5 \text { = very often } \\
\text { High values represent high perceived stress. }\end{array}$ \\
\hline $\begin{array}{l}\text { Self-regulation (Freund \& } \\
\text { Baltes, 2002; Ziegelmann } \\
\text { \& Lippke, 2006) }[32,33]\end{array}$ & $\begin{array}{l}\text { 1. I do everything I can to realize my plans. }\left(^{*}\right) \\
\text { 2. I have set my goals clearly and stick to } \\
\text { them. }\left(^{*}\right) \\
\text { 3. When it becomes harder for me to get the } \\
\text { same results, I keep } \\
\text { trying harder until I can do it as well as } \\
\text { before. }\left(^{*}\right) \\
\text { 4. When I can't do something important the } \\
\quad \text { way I did before, } \\
\text { I look for a new goal. }\left(^{*}\right) \\
\text { Scale represents the mean of at least } 2 \text { required } \\
\text { valid items, all items have been recoded. } \\
1 \text { = strongly agree } \\
2=\text { agree } \\
3=\text { disagree } \\
4=\text { strongly disagree } \\
\text { High values represent high self-regulation. }\end{array}$ \\
\hline
\end{tabular}

Items with asterisk have been recoded

groups than in the group of the occasional drinkers. Life satisfaction increased with more regular alcohol consumption, negative affect decreased consistently, while positive affect, optimism, and self-esteem was highest in the group of occasional drinkers. The level of perceived stress decreased with increased alcohol consumption. Self-efficacy was higher in the group of occasional drinkers compared with the non-drinking group.

\section{Regression analysis}

Table 3 and Table 4 show results of fully adjusted multinomial logit regression analyses with the drinking status (non-drinking; occasional drinking; daily drinking) as dependent variable, with non-drinking as reference category. For reasons of clarity, the results of multinomial regression analyses were displayed in two tables (Table 3: non-drinking vs. occasional drinking; Table 4: non-drinking vs. daily drinking). Relative risk ratios were reported. It was adjusted for age, gender, marital status, income, region, physical activity and the number of chronic conditions. Based on theoretical considerations and empirical studies, these variables were selected. Thus, stepwise regression models were not used. The psychological factors were entered separately in the regression models. Consequently, nine multinomial regression models were computed.

In all regression models, the number of physical illnesses was negatively associated with a more regular consumption of alcohol (for example, in the model with loneliness as independent variable; occasional drinkers: relative risk ratio $=0.90$ [95\% CI: $0.87-0.94]$; daily drinkers: 0.92 [0.87-0.97]). Furthermore, women drank less frequently alcohol than men (occasional drinkers: $0.72[0.61-0.84]$; daily drinkers: 0.23 [0.18-0.28]). The individual mean net equivalent income per month (in $€ 1000)$ was positively associated with the occasional drinker status (1.37 [1.24-1.51]) and in particular with the status as daily drinker (1.50 [1.35-1.67]).

With respect to the psychological variables, occasional drinkers and daily drinkers were less affected by loneliness than the never drinking group (occasional drinkers: 0.77 [0.67-0.89]; daily drinkers: 0.81 [0.67-0.97]). Besides, life satisfaction (occasional drinkers: 1.35 [1.221.50]; daily drinkers: 1.32 [1.15-1.52]) and positive affect (occasional drinkers: 1.40 [1.21-1.62]; daily drinkers: 1.50 [1.24-1.83]) was higher in both groups. In addition, the level of optimism was higher for occasional (1.36 [1.19-1.56]) and daily drinkers (1.25 [1.04-1.50]) than for never drinkers. The same applies to self-esteem (occasional drinkers: 1.29 [1.07-1.55]; daily drinkers: 1.30 [1.01-1.66]). In contrast, perceived stress was higher for the group of never drinkers as compared to occasional (0.78 [0.70-0.88]) and daily drinkers (0.69 [0.59-0.81]). With respect to self-efficacy, the regression analysis showed a significant difference for occasional drinkers, who were characterized by having a higher self-efficacy as compared to the never drinkers (1.21 [1.02-1.43]), whereas daily drinkers did not differ significantly from this reference group.

Furthermore, differences between occasional and daily drinkers were examined (results not shown, but available upon request). Except for slight differences in perceived stress, which was negatively associated with being a daily drinker, psychological factors did not significantly vary between occasional and daily drinkers. Besides, daily drinking was positively associated with being male, higher income, living in West Germany, and age.

In additional analysis, depression was added to the main model (results not shown). Multinomial regressions showed that compared with non-drinking, occasional and daily drinking were negatively associated with depression. Beyond the association between alcohol consumption and depression, there remained an independent association between alcohol consumption (Ref.: non-drinking) and life satisfaction (occasional drinking; daily drinking), positive affect (occasional drinking; daily drinking), optimism (occasional drinking), and perceived stress (occasional drinking; daily drinking). Furthermore, an association between alcohol consumption and negative affect was observed (daily drinking).

Moreover, regression analysis stratified by age $(<65$ years; $\geq 65$ years) showed that particularly in individuals aged 40 to 64 years, the association between psychological factors 
Table 2 Characteristics, stratified by alcohol consumption $(n=7820)$

\begin{tabular}{|c|c|c|c|c|c|c|c|}
\hline & \multicolumn{2}{|c|}{$\begin{array}{l}\text { Persons who never drink } \\
\text { alcohol }(n=896 ; 11.5 \%)\end{array}$} & \multicolumn{2}{|c|}{$\begin{array}{l}\text { Persons who drink alcohol at least } \\
\text { 'rarer than once a month' to 'several } \\
\text { times a week' }(n=5986 ; 76.5 \%)\end{array}$} & \multicolumn{2}{|c|}{$\begin{array}{l}\text { Persons who drink } \\
\text { alcohol daily ( } n=938 ; 12.0 \%)\end{array}$} & \multirow[t]{2}{*}{$p$-value +} \\
\hline & N/Mean & $\% /(S D)$ & N/Mean & $\% /(S D)$ & N/Mean & $\% /(S D)$ & \\
\hline Gender: Female & 547 & $61.1 \%$ & 3200 & $53.5 \%$ & 235 & $25.1 \%$ & $p<.001$ \\
\hline Age in years & 66.79 & $(11.31)$ & 63.77 & $(11.24)$ & 66.89 & $(10.47)$ & $p<.001$ \\
\hline Marital status & & & & & & & $p<.001$ \\
\hline Married and living together with spouse & 538 & $60.2 \%$ & 4223 & $70.7 \%$ & 704 & $75.1 \%$ & \\
\hline Married, living separated from spouse & 13 & $1.4 \%$ & 97 & $1.6 \%$ & 16 & $1.7 \%$ & \\
\hline Divorced & 117 & $13.1 \%$ & 601 & $10.1 \%$ & 66 & $7.0 \%$ & \\
\hline Widowed & 159 & $17.8 \%$ & 624 & $10.4 \%$ & 92 & $9.8 \%$ & \\
\hline Single & 67 & $7.5 \%$ & 427 & $7.2 \%$ & 60 & $6.4 \%$ & \\
\hline Monthly net equivalent income $(€)$ & 1547.99 & $(1361.48)$ & 1960.99 & $(1341.80)$ & 2205.92 & $(1525.89)$ & $p<.001$ \\
\hline Region: West Germany & 595 & $66.4 \%$ & 3988 & $66.6 \%$ & 672 & $71.6 \%$ & $p<.01$ \\
\hline Physical activity & & & & & & & $p<.001$ \\
\hline - daily & 79 & $8.8 \%$ & 501 & $8.4 \%$ & 74 & $7.9 \%$ & \\
\hline - several times a week & 164 & $18.3 \%$ & 1738 & $29.0 \%$ & 232 & $24.7 \%$ & \\
\hline - once a week & 120 & $13.4 \%$ & 1136 & $19.0 \%$ & 174 & $18.5 \%$ & \\
\hline - one to three times a month & 39 & $4.4 \%$ & 468 & $7.8 \%$ & 77 & $8.2 \%$ & \\
\hline - less frequently & 89 & $9.9 \%$ & 711 & $11.9 \%$ & 115 & $12.3 \%$ & \\
\hline - never & 405 & $45.2 \%$ & 1431 & $23.9 \%$ & 266 & $28.4 \%$ & \\
\hline Number of physical illnesses & 3.19 & $(2.13)$ & 2.49 & $(1.84)$ & 2.72 & $(1.77)$ & $p<.001$ \\
\hline Loneliness & 1.88 & $(0.60)$ & 1.76 & $(0.53)$ & 1.78 & $(0.54)$ & $p<.001$ \\
\hline Life satisfaction & 3.58 & $(0.84)$ & 3.83 & $(0.70)$ & 3.84 & $(0.73)$ & $p<.001$ \\
\hline Positive affect & 3.40 & $(0.61)$ & 3.57 & $(0.52)$ & 3.56 & $(0.52)$ & $p<.001$ \\
\hline Negative affect & 2.13 & $(0.58)$ & 2.09 & $(0.52)$ & 2.06 & $(0.52)$ & $p<.05$ \\
\hline Optimism & 2.80 & $(0.64)$ & 3.00 & $(0.53)$ & 2.96 & $(0.56)$ & $p<.001$ \\
\hline Self-efficacy & 3.00 & $(0.52)$ & 3.08 & $(0.42)$ & 3.08 & $(0.44)$ & $p<.001$ \\
\hline Self-esteem & 3.31 & $(0.46)$ & 3.41 & $(0.40)$ & 3.40 & $(0.40)$ & $p<.001$ \\
\hline Self-regulation & 3.99 & $(0.59)$ & 3.98 & $(0.50)$ & 3.96 & $(0.53)$ & $p=.50$ \\
\hline Perceived stress & 2.55 & $(0.71)$ & 2.35 & $(0.64)$ & 2.28 & $(0.67)$ & $p<.001$ \\
\hline Depression & 122 & $13.9 \%$ & 324 & $5.5 \%$ & 41 & $4.5 \%$ & $p<.001$ \\
\hline
\end{tabular}

† Analyses of variance were used for the continuous variables, and chi-squared tests for all other variables; Loneliness [23]; Life satisfaction (SWLS, [25]); Positive and negative affect (PANAS, [26]); Optimism [28]; Self-efficacy [29]; Self-esteem [30]; Self-regulation [33]; Perceived stress [31], Depression (CES-D $\geq 18$ )

and alcohol consumption was similar in terms of effect sizes and significance, compared with the main model (total sample). This means that loneliness, life satisfaction, positive affect, optimism, self-esteem and perceived stress were significantly associated with alcohol consumption. These results are displayed in the Additional files 1, 2, 3, 4.

Furthermore, we acknowledge the fact that the physical illnesses used in the current study are difficult to compare. Consequently, we performed a sensitivity analysis where all the physical illnesses were entered as dummy-variables in the model. However, results remained virtually the same (not shown, but available upon request).

\section{Discussion}

The aim of the study was to identify factors associated with alcohol intake in older adults, particularly focusing on psychological factors and using a population-based sample of community-dwelling individuals in the second half of life. $11.5 \%$ of the individuals never drank alcohol, $76.5 \%$ drank alcohol occasionally, and $12.0 \%$ drank alcohol every day. After adjusting for various potential confounders, multinomial logistic regressions revealed that in contrast to never drinkers, both occasional and daily drinkers had a decreased loneliness, a higher satisfaction with life, a higher positive affect, a higher optimism, a higher self-efficacy (occasional drinkers only), a 


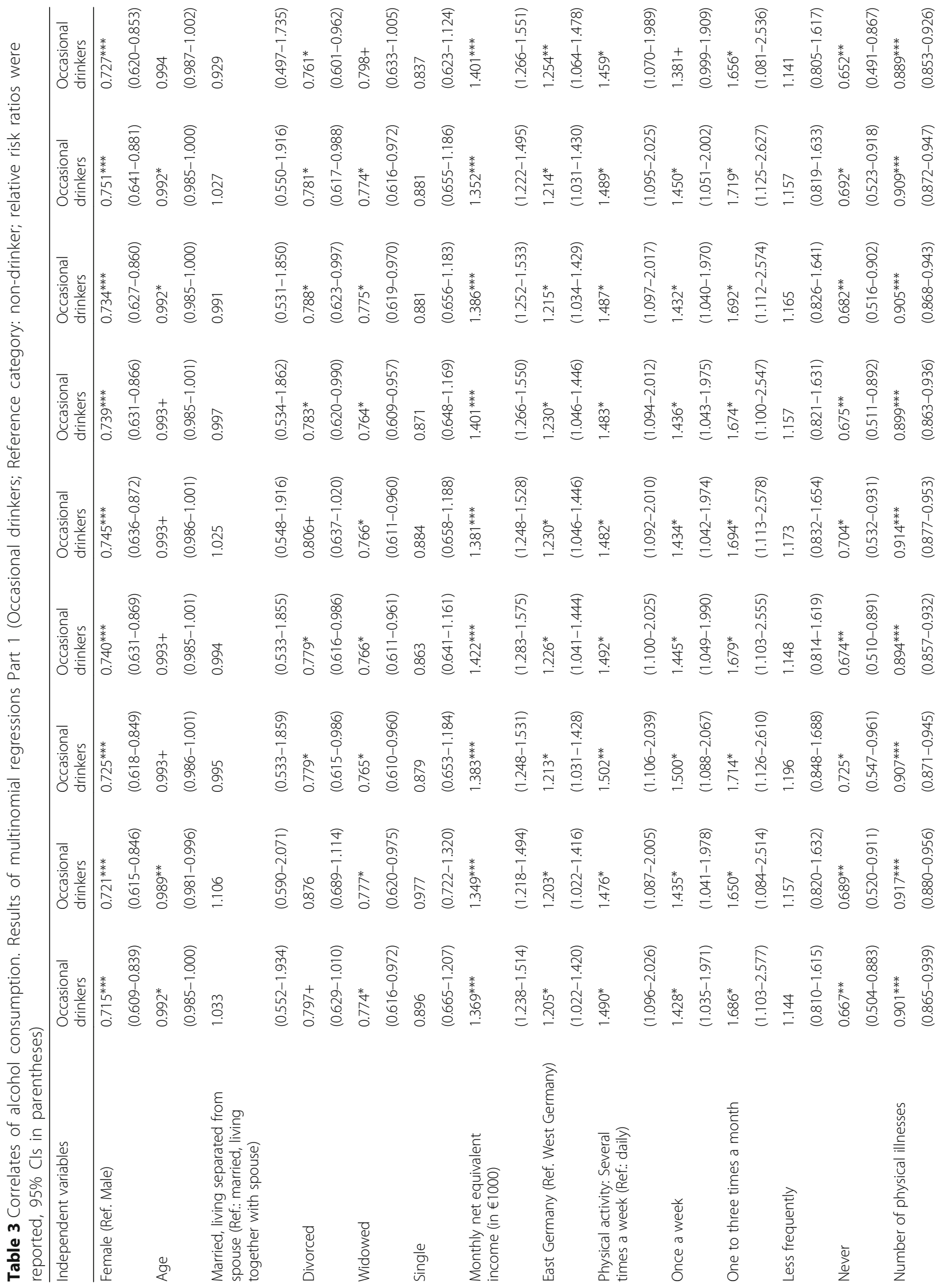




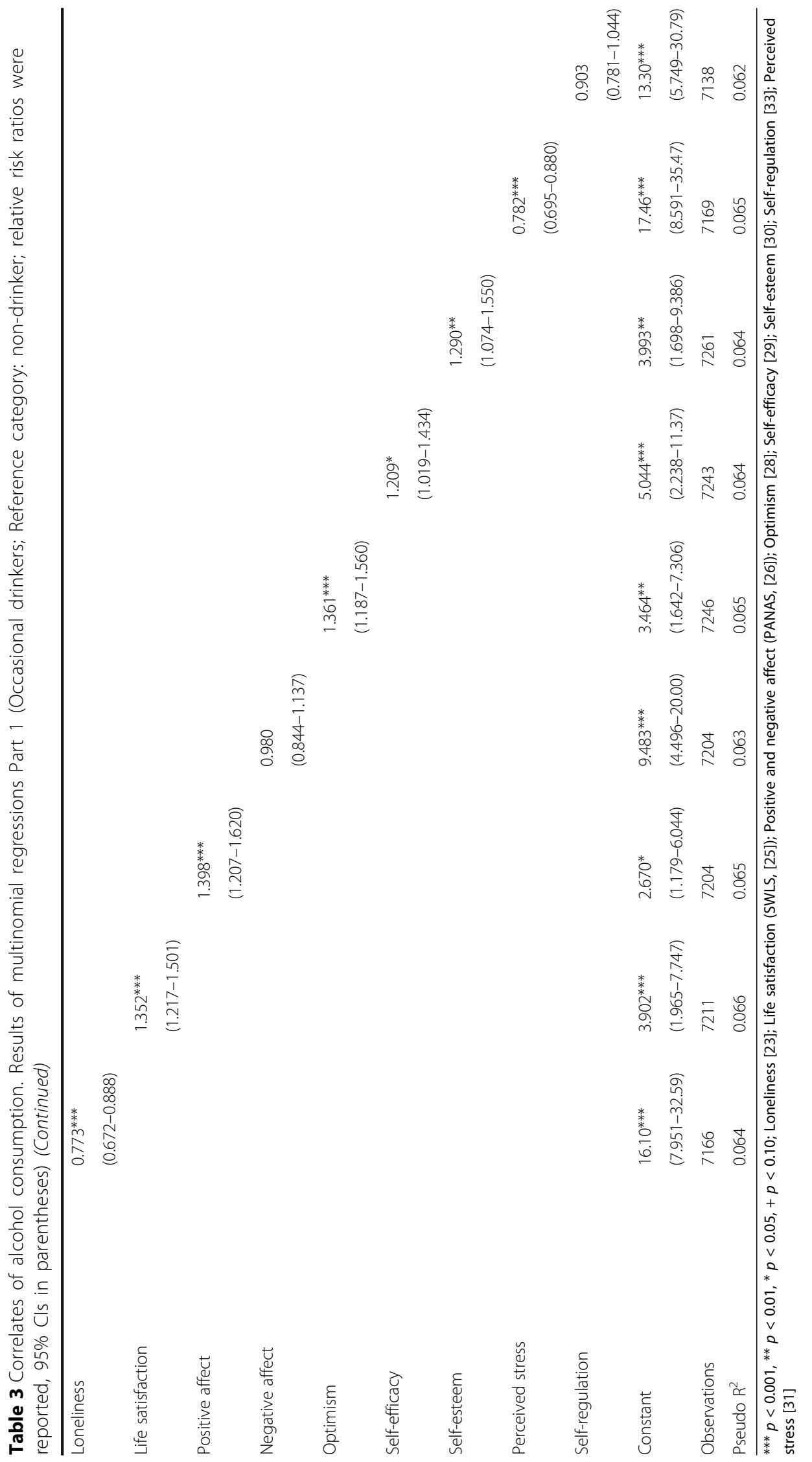




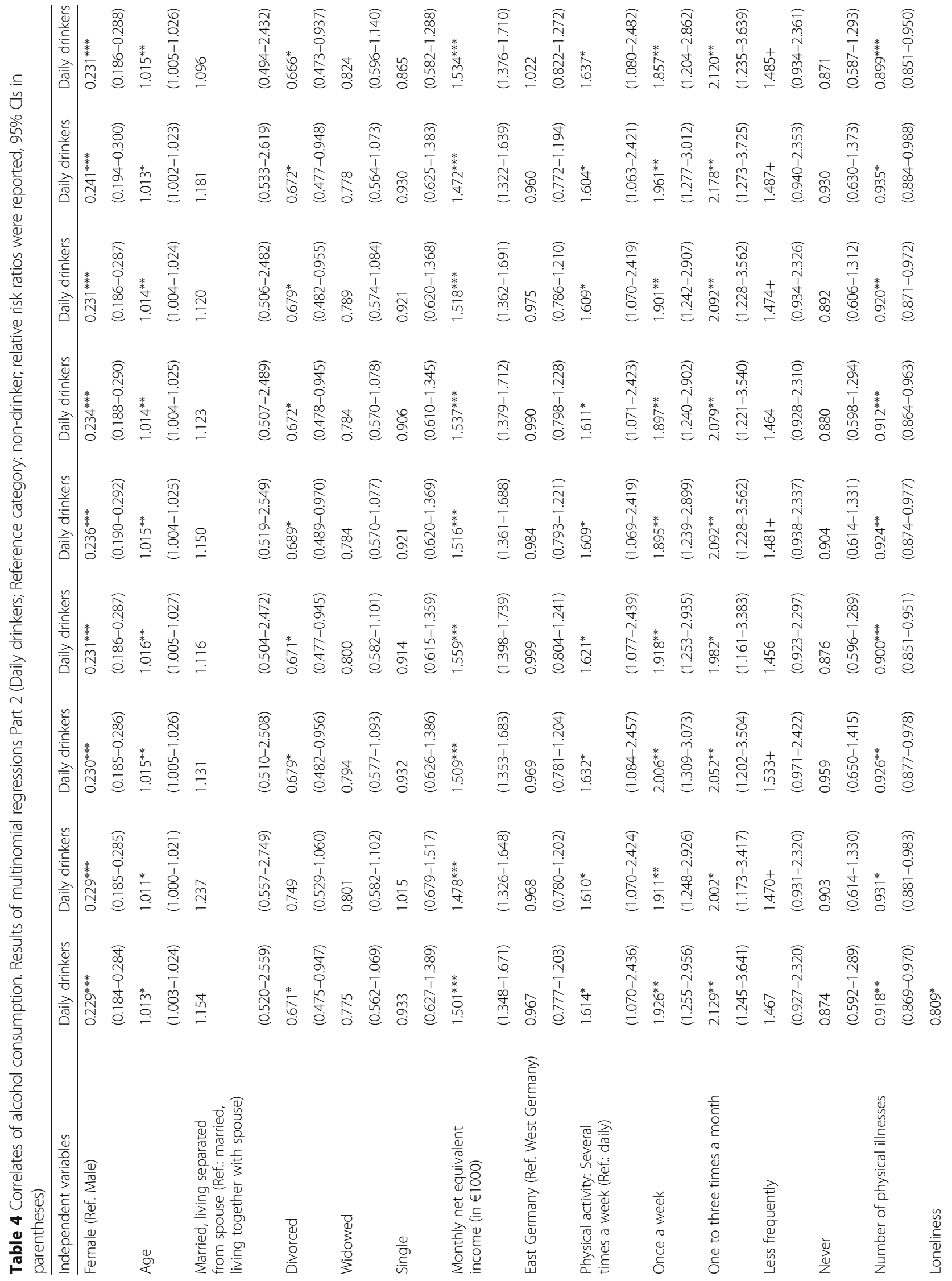




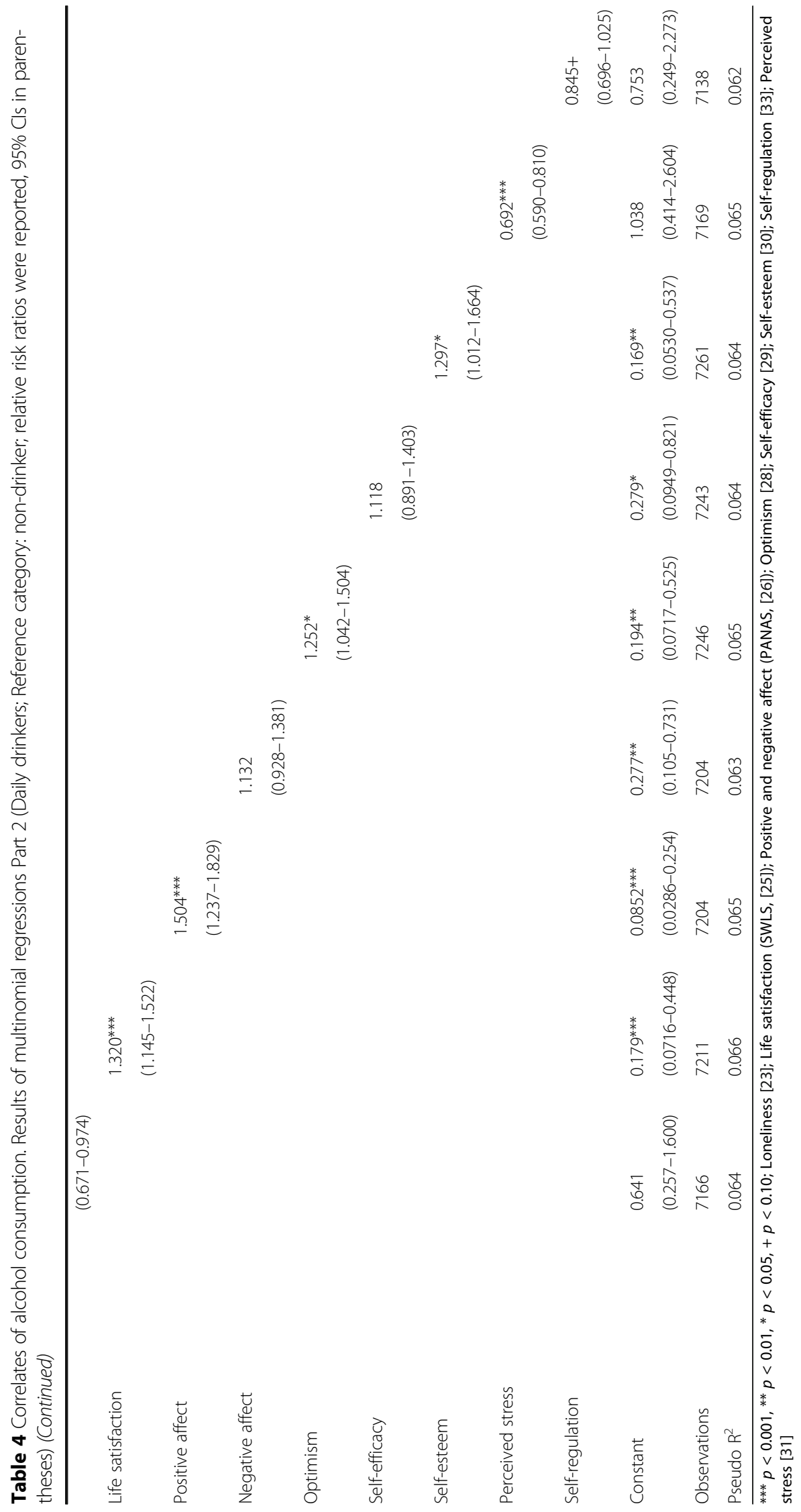


higher self-esteem, and less perceived stress. However, as compared with never drinkers, there were no significant differences in negative affect, and self-regulation. Besides, as compared with never drinking, occasional and daily drinking were positively associated with less physical illnesses, male gender, and income.

Except for marked sex differences, daily drinkers were similar regarding the independent variables compared with occasional drinkers. This is in accordance with a random sample of patients from General Practice registers in London $(n=241)$ [38].

Using college student heavy drinkers $(n=170$; mean age: $19.2 \pm 0.8$ ) from a private university in New York, Hustad et al. [7] showed that self-regulation was negatively related with alcohol consumption. Furthermore, Zullig et al. [9] showed that life satisfaction was negatively related with regular alcohol use in sample of South Carolina public high school students in grades 9-12 $(n=5032)$. In contrast, the current study revealed that compared with never drinking, favorable levels of the independent variables, like more optimism, a lower illness level or higher self-esteems, were associated with occasional and daily drinking. A possible explanation might be that a large proportion of these non-drinkers are assumed to be ex-drinkers (with high prevalence rates of various chronic conditions), which would be in accordance with previous findings $[39,40]$. This might explain why non-drinkers tend to suffer from multiple chronic conditions (see Table 2) as a consequence of sustained drinking that had taken place in the past years, supporting the idea that these individuals are abstinent from alcohol for health reasons ("sick quitter effect") [40, 41].

In total, the present study is one of the first studies examining factors associated with drinking behavior in the second half of life with a particular focus on psychological factors. Many previous studies focused on adolescents or young adults, whereas only little evidence is available regarding older populations. The latter studies focused in general on a single psychological construct related to the drinking behavior. Our study provides further insights into the relationship of important determinants including various psychological constructs using well-established instruments with drinking behavior among older adults based on a nationally representative study.

Data from the current study were gathered from a large, representative sample of community-dwelling individuals in the second half of life. The psychological factors examined in our study were operationalized using established and well-accepted measures. In addition, a number of control variables deemed to be important predictors of alcohol intake have been included in the analysis. The present study adds new insights into the relation between factors associated with alcohol intake in older individuals.
The present study also has some limitations that warrant consideration. As indicated by the response rates in the German Ageing Survey, a sample selection bias cannot be ruled out. Thus, it might be difficult to generalize the results to, e.g., individuals with low education or bad subjective health [42]. Moreover, self-rated daily alcohol intake might not fully reflect factual risky alcohol use in the current cross-sectional study, i.e. individuals might not report their drinking accurately. However, it has been demonstrated that self-report methods offer a valid approach to measuring this variable $[43,44]$. In addition, the frequency of alcohol consumption does not allow assessing the volume of alcohol intake. Consequently, our data cannot reflect, e.g., binge drinking. Future studies might concentrate on such an outcome measure. Furthermore, it is worth noting that daily alcohol consumptions does not always reflect risky alcohol use. On the contrary, non-daily drinking might sometimes reflect risky drinking. Moreover, our outcome variable (frequency of alcohol consumption) cannot differentiate between non-drinkers and ex-drinkers. This is a main limitation of the current study.

\section{Conclusions}

The current study stresses particularly the relationship between general psychological factors and (risky) alcohol intake in the second half of life. Since interventions are available to address this risk factor [45], this might help to identify individuals with increased alcohol consumption. Upcoming longitudinal studies are required to gain further insights into the determinants of alcohol consumption. Using panel regressions models can help to overcome the shortcomings of cross-sectional observational studies (e.g., self-selection).

\section{Additional files}

Additional file 1: Correlates of alcohol consumption among individuals aged 40 to 64 years. Results of multinomial regressions Part 1 (Occasional drinkers; Reference category: non-drinker; relative risk ratios were reported, 95\% Cls in parentheses). (DOCX $18 \mathrm{~kb}$ )

Additional file 2: Correlates of alcohol consumption among individuals aged 40 to 64 years. Results of multinomial regressions Part 2 (Daily drinkers; Reference category: non-drinker; relative risk ratios were reported, $95 \% \mathrm{Cls}$ in parentheses). (DOCX $18 \mathrm{~kb}$ )

Additional file 3: Correlates of alcohol consumption among individuals aged 65 years and above. Results of multinomial regressions Part 1 (Occasional drinkers; Reference category: non-drinker; relative risk ratios were reported, 95\% Cls in parentheses). (DOCX 18 kb)

Additional file 4: Correlates of alcohol consumption among individuals aged 65 years and above. Results of multinomial regressions Part 2 (Daily drinkers; Reference category: non-drinker; relative risk ratios were reported, $95 \%$ Cls in parentheses). (DOCX $17 \mathrm{~kb}$ )

\section{Abbreviations}

DEAS: German Ageing Survey; OECD: Organization for Economic Co-Operation and Development; PANAS: Positive and Negative Affect Schedule; SWLS: Satisfaction with Life Scale 


\section{Acknowledgements}

Not applicable.

\section{Funding}

None.

\section{Availability of data and materials}

The data used in this study are third-party data. The anonymized data sets of the DEAS $(1996,2002,2008,2011$, and 2014) are available for secondary analysis. The data has been made available to scientists at universities and research institutes exclusively for scientific purposes. The use of data is subject to written data protection agreements. Microdata of the German Ageing Survey (DEAS) is available free of charge to scientific researchers for non-profitable purposes. The FDZ-DZA provides access and support to scholars interested in using DEAS for their research. However, for reasons of data protection, signing a data distribution contract is required before data can be obtained. Please see for further Information (data distribution contract): https://www.dza.de/ en/fdz/access-to-data/formular-deas-en-english.html.

\section{Authors' contributions}

AH, JOB, SW, HHK: Design and concept of analyses, preparation of data, statistical analysis and interpretation of data, preparing of the manuscript. All authors critically reviewed the manuscript, provided significant editing of the article and approved the final manuscript. All authors read and approved the final manuscript.

\section{Ethics approval and consent to participate}

Please note that an ethical statement for the DEAS study was not necessary because criteria for the need of an ethical statement were not met (risk for the respondents, lack of information about the aims of the study, examination of patients). This is in accordance with the German Research Foundationguidelines (Deutsche Forschungsgemeinschaft, DFG) available at: http://dfg.de/ foerderung/faq/geistes_sozialwissenschaften/ (only available in German language).

The German Centre of Gerontology (DZA) decided that an ethical statement was not necessary. It is worth noting that the DEAS study has a permanent advisory board. Prior to each wave of data collection, the permanent advisory board received detailed information about the sampling method, the consent to participate and the instruments used in the DEAS study. The permanent advisory board concluded that the DEAS study did not need approval from an ethics committee. This procedure is in concordance with local guidelines. Please also see the RatSWD (Principles and Review Procedures of Research Ethics in the Social and Economic Sciences): https:// www.ratswd.de/dl/RatSWD_Output9_Forschungsethik.pdf, page 28 (only available in German language).

Prior to the interview, written informed consent was given by all participants of the study.

\section{Consent for publication}

Not applicable.

\section{Competing interests}

The authors declare that they have no competing interests.

\section{Publisher's Note}

Springer Nature remains neutral with regard to jurisdictional claims in published maps and institutional affiliations.

\section{Author details}

${ }^{1}$ Department of Health Economics and Health Services Research, Hamburg Center for Health Economics, University Medical Center Hamburg-Eppendorf, Hamburg, Germany. ${ }^{2}$ Central Institute of Mental Health, Medical Faculty Mannheim/Heidelberg University, Mannheim, Germany.

\section{Received: 19 December 2016 Accepted: 21 August 2017}

\section{Published online: 08 September 2017}

\section{References}

1. Lim SS, Vos T, Flaxman AD, Danaei G, Shibuya K, Adair-Rohani H, AlMazroa MA, Amann M, Anderson HR, Andrews KG. A comparative risk assessment of burden of disease and injury attributable to 67 risk factors and risk factor clusters in 21 regions, 1990-2010: a systematic analysis for the global burden of disease study 2010. Lancet. 2013:380(9859):2224-60.

2. Alcohol [http://www.who.int/mediacentre/factsheets/fs349/en/].

3. Reczek C, Pudrovska T, Carr D, Thomeer MB, Umberson D. Marital histories and heavy alcohol use among older adults. J Health Soc Behav. 2016:57(1):77-96.

4. Dillard AJ, Midboe AM, Klein W. M.: the dark side of optimism: unrealistic optimism about problems with alcohol predicts subsequent negative event experiences. Personal Soc Psychol Bull. 2009;35(11):1540-50.

5. Gilles DM, Turk CL, Fresco DM. Social anxiety, alcohol expectancies, and selfefficacy as predictors of heavy drinking in college students. Addict Behav. 2006;31:388-98.

6. Griffin KW, Lowe SR, Acevedo BP, Botvin GJ. Affective self-regulation trajectories during secondary school predict substance use among urban minority young adults. J Child Adolesc Subst Abuse. 2015;24(4):228-34.

7. Hustad JTP, Carey KB, Carey MP, Maisto SA. Self-regulation, alcohol consumption, and consequences in college student heavy drinkers: a simultaneous latent growth analysis. J Stud Alcohol Drugs. 2009;70(3):37382.

8. Steptoe A, Wardle J, Pollard TM, Canaan L, Davies GJ. Stress, social support and health-Realted behavior: a study of smoking, alcohol consumption and physical exercise. J Psychosom Res. 1996;41(2):171-80.

9. Zullig KJ, Valois RF, Huebner ES, Oeltmann JE, Drane JW. Relationship between perceived life satisfaction and adolescents' substance abuse. J Adolesc Health. 2001;29:279-88.

10. Wills TA, DuHamel K, Vaccaro D. Activity and mood temperament as predictors of adolescent substance use: test of a self-regulation Mediational model. J Pers Soc Psychol. 1995;68(5):901-16.

11. Blazer DG, Wu L-T. The epidemiology of at-risk and binge drinking among middle-aged and elderly community adults: National Survey on drug use and health. Am J Psychiatry. 2009;166(10):1162-9.

12. Byrne GJ, Raphael B, Arnold E. Alcohol consumption and psychological distress in recently widowed older men. Aust N Z J Psychiatry. 1999;33(5):740-7.

13. Saunders P, Copeland J, Dewey M, Davidson I, McWilliam C, Sharma V, Sullivan C. Heavy drinking as a risk factor for depression and dementia in elderly men. Findings from the Liverpool longitudinal community study. $\mathrm{Br}$ J Psychiatry. 1991;159(2):213-6.

14. Breslow RA, Faden VB, Smothers B. Alcohol consumption by elderly Americans. J Stud Alcohol. 2003;64(6):884-92.

15. National Institute on Alcohol Abuse and Alcoholism. Alcohol and aging. Alcohol Alert. 1998;40:1-6.

16. Low-risk alcohol drinking advice. http://www.alcohol.org.nz/help-advice/ advice-on-alcohol/low-risk-alcohol-drinking-advice.

17. Marmorstein NR. Longitudinal associations between alcohol problems and depressive symptoms: early adolescence through early adulthood. Alcohol Clin Exp Res. 2009;33(1):49-59.

18. Glindemann KE, Geller ES, Fortney JN. Self-esteem and alcohol consumption: a study of college drinking behavior in a naturalistic setting. J Alcohol Drug Educ. 1999:45(1):60-71.

19. Sitharthan T, Job R, Kavanagh DJ, Sitharthan G, Hough M. Development of a controlled drinking self-efficacy scale and appraising its relation to alcohol dependence. J Clin Psychol. 2003;59(3):351-62.

20. Klaus D, Engstler H, Mahne K, Wolff JK, Simonson J, Wurm S, TeschRömer C. Cohort profile: the German Ageing Survey (DEAS). Int J Epidemiol. 2017:42:dyw326-4

21. Börsch-Supan A, Brandt M, Hunkler C, Kneip T, Korbmacher J, Malter F, Schaan B, Stuck S, Zuber S. Data resource profile: the survey of health, ageing and retirement in Europe (SHARE). Int J Epidemiol. 2013;42(4):dyt088

22. Neller K. Kooperation und Verweigerung. Eine Non-Response-Studie [co-operation and refusal: a non-response study]. ZUMA Nachrichten. 2005;29(57):9-36.

23. Gierveld JDJ, Van Tilburg T. A 6-item scale for overall, emotional, and social loneliness confirmatory tests on survey data. Res Aging. 2006;28(5):582-98.

24. Gierveld JDJ, Van Tilburg T. The de Jong Gierveld short scales for emotional and social loneliness: tested on data from 7 countries in the UN generations and gender surveys. Eur J Ageing. 2010;7(2):121-30.

25. Pavot W, Diener E. Review of the satisfaction with life scale. Psychol Assess. 1993:5(2):164-72

26. Watson D, Clark LA, Tellegen A. Development and validation of brief measures of positive and negative affect: the PANAS scales. J Pers Soc Psychol. 1988;54(6):1063-70. 
27. Crawford JR, Henry JD. The positive and negative affect schedule (PANAS): construct validity, measurement properties and normative data in a large non-clinical sample. Br J Clin Psychol. 2004;43(3):245-65.

28. Brandtstädter J, Wentura D. Veränderungen der Zeit-und Zukunftsperspektive im Übergang zum höheren Erwachsenenalter: entwicklungspsychologische und differentielle Aspekte [changes in time perspectives and attitudes toward the future during the transition to later adulthood: developmental psychology and differential aspects]. Z Entwicklungspsychol Padagog Psychol. 1994;26(1):2-21.

29. Schwarzer R, Jerusalem M. Skalen zur Erfassung von Lehrer-und Schülermerkmalen. Dokumentation der psychometrischen Verfahren im Rahmen der Wissenschaftlichen Begleitung des Modellversuchs Selbstwirksame Schulen Berlin. 1999.

30. Rosenberg M. Society and the adolescent self-image. Princeton University Press: Princeton; 1965

31. Cohen S, Kamarck T, Mermelstein R. A global measure of perceived stress. J Health Soc Behav. 1983;24:385-96.

32. Ziegelmann JP, Lippke S. Selbstregulation in der Gesundheitsverhaltensänderung: Strategienutzung und Bewältigungsplanung im jungen, mittleren und höheren Alter. Z Gesundheitspsychol. 2006;14(2):82-90.

33. Freund AM, Baltes PB. Life-management strategies of selection optimization and compensation: measurement by self-report and construct validity. JPSP. 2002;82(4):642

34. Warner LM, Ziegelmann JP, Schüz B, Wurm S, Tesch-Römer C, Schwarzer R. Maintaining autonomy despite multimorbidity: self-efficacy and the two faces of social support. Eur J Ageing. 2011;8(1):3-12.

35. Boden JM, Fergusson DM. Alcohol and depression. Addiction. 2011;106(5):906-14.

36. Fergusson DM, Boden JM, Horwood LJ. Tests of causal links between alcohol abuse or dependence and major depression. Arch Gen Psychiatry. 2009;66(3):260-6.

37. Luhmann M, Hofmann W, Eid M, Lucas RE. Subjective well-being and adaptation to life events: a meta-analysis. J Pers Soc Psychol. 2012;102(3):592-615.

38. Iliffe S, Haines A, Booroff A, Goldenberg E, Morgan P, Gallivan S. Alcohol consumption by elderly people: a general practice survey. Age Ageing. 1991;20(2):120-3.

39. Caldwell T, Rodgers B, Power C, Clark C, Stansfeld S. Drinking histories of self-identified lifetime abstainers and occasional drinkers: findings from the 1958 British birth cohort study. Alcohol Alcohol. 2006;41(6):650-4.

40. Shaper A. Alcohol and mortality: a review of prospective studies. Br J Addict. 1990;85(7):837-47.

41. Wannamethee G, Shaper A. Changes in drinking habits in middle-aged British men. JR Coll Gen Pract. 1988;38(315):440-2.

42. Schiel S, Knerr P, Dickmann C, Aust F. Deutscher Alterssurvey (DEAS): Methodenbericht zur Durchführung der fünften Erhebungswelle 2014. infas: Bonn; 2015.

43. Del Boca FK, Darkes J. The validity of self-reports of alcohol consumption: state of the science and challenges for research. Addiction. 2003;98(s2):1-12.

44. Simons JS, Wills TA, Emery NN, Marks RM. Quantifying alcohol consumption: self-report, transdermal assessment, and prediction of dependence symptoms. Addict Behav. 2015;50:205-12.

45. Bien TH, Miller WR, Tonigan JS. Brief interventions for alcohol problems: a review. Addiction. 1993;88(3):315-36.

\section{Submit your next manuscript to BioMed Central and we will help you at every step:}

- We accept pre-submission inquiries

- Our selector tool helps you to find the most relevant journal

- We provide round the clock customer support

- Convenient online submission

- Thorough peer review

- Inclusion in PubMed and all major indexing services

- Maximum visibility for your research

Submit your manuscript at www.biomedcentral.com/submit

Biomed Central 